\title{
To study the neonatal outcomes in pregnancies with hypothyroidism in a tertiary referral centre
}

\author{
Shameel Faisal*, Satish Tibrewala, Sana Afreen, Raksha Shetty
}

Department of Obstetrics and Gynaecology, Bombay Hospital Institute of Medical Sciences, Mumbai, Maharashtra, India

Received: 24 July 2016

Accepted: 01August 2016

*Correspondence:

Dr. Shameel Faisal,

E-mail: shameelfaisal@gmail.com

Copyright: () the author(s), publisher and licensee Medip Academy. This is an open-access article distributed under the terms of the Creative Commons Attribution Non-Commercial License, which permits unrestricted non-commercial use, distribution, and reproduction in any medium, provided the original work is properly cited.

\begin{abstract}
Background: Maternal hypothyroidism may be associated with a variety of adverse maternal fetal outcomes, whether those outcomes are affected by the maternal thyroid status during her antenatal periods remains yet to be clear. The prospective observational study was done and investigated the maternal foetal and neonatal outcomes in patients with hypothyroidism during their antenatal period. Maternal thyroid-stimulating hormone (TSH), free thyroxine (FT4) and free triiodothyronine (FT3) and newborn serum levels were also evaluated.

Methods: A prospective observational study was done. Group of 100 pregnancies with hypothyroidism managed in the antenatal clinic were studied at tertiary referral centre. Analysis of the neonatal outcome and modes of deliveries were evaluated.

Results: The caesarean section rates were higher in the study group (40\%). The neonatal TSH at birth were also evaluated in both the groups and there is no significant differences noted in both the groups $\mathrm{p}$ value $=0.3821$. The prevalence of preterm babies, low birth weight babies (birth weight less than $2.5 \mathrm{~kg}$ ) and foetal distress were significantly higher in the uncontrolled hypothyroid status group as compared to well controlled thyroid status groups. Conclusions: The maternal thyroid status plays very imp role in the foetal outcome. The study shows strong association between of the increased rates of caesarean sections, low birth weight, preterm delivery, foetal distress and uncontrolled hypothyroid status as compared with the ones with euthyroid functions. Hence it was concluded that early diagnosis and timely management of hypothyroidism in pregnancy is important to prevent materno foetal complications.
\end{abstract}

Keywords: Hypothyroidism, Caesarean section, Fetal distress, Preterm delivery, Low birth weight, Fetal distress

\section{INTRODUCTION}

Thyroid diseases are the commonest endocrine disorders affecting women of reproductive age group and hence constitute the commonest endocrine disorder in pregnancy also. It has long been recognized that maternal thyroid hormone excess or deficiency can influence the outcome for mother and fetus at all stages of pregnancy as well as interfere with ovulation and fertility. ${ }^{1,2}$ Maternal hypothyroidism is the most common disorder of thyroid function in pregnancy and has been associated with spontaneous pregnancy loss, pre eclampsia, preterm delivery, antepartum hemorrhage, low birth weight, fetal distress and reduced intellectual function of the offspring. Thyroid dysfunction is often overlooked in pregnant women because of the nonspecific symptoms and hypermetabolic state of pregnancy.

Hence thyroid function tests become essential to know the thyroid status in pregnancy. ${ }^{3}$ 


\section{METHODS}

The study was designed as a prospective cohort and was carried out from December 2012 to November 2014 in a private tertiary care teaching hospital. Ethics committee approval was obtained. Due to purely observational nature of the study, informed consent were not obtained. All 100 cohort cases are selected prospectively from consecutive pregnant female in the antenatal clinics of tertiary referral centre in the study period of two years.

\section{Inclusion criteria}

All the pregnant females are included irrespective of their gravid status and multiple pregnancies are also included.

They would be subjected to clinical evaluation. Serum TSH was done in all as initial investigation and subject are then grouped based on results.

- Group A: Patient with known hypothyroidism before pregnancy.

- Group B: Patient with hypothyroidism first diagnosed during pregnancy.

Once the treatment was started TSH was repeated after 6 weeks.

Fetal monitoring of the patient with thyroid disorder was done using USG every three month focusing on fetal heart rate (FHR), fetal growth, fetal movements.

The patients in both the groups were followed up till the termination or final outcome of the pregnancy.

At the end of the study, the different study variables of both the groups were compared and analysed

Outcomes were evaluated in terms of variables

- Rate of cesarean section (including both elective and emergency).

- Rate of vaginal delivery.

- Rate of instrumental delivery.

- Neonatal birth weight.

- Prevalence of low birth weight $(2.5 \mathrm{~kg})$.

- Prevalence of preterm delivery.

- Incidence of fetal distress.

- Measurement of newborn serum TSH at birth.

- Prevalence of NICU admission.

- Incidence of neonatal complications.

- Apgar score at birth.

- Incidence of congenital hypothyroidism.

TSH was estimated by CLIA (chemi luminescent immunometric assay).

FT3/FT4 estimation was done by CLIA (chemi luminescent immunometric assay).

\section{Statistical analysis}

The continuous variables used in the data were represented as mean (standard deviation, SD) or median (interquartile range, IQR) while the categorical data was represented as percentages. For the comparison of continuous data student unpaired t-test was used. For comparing the categorical variables chi square test was used.

Value of less than 0.05 is to be considered as significant. The relative risks were calculated wherever required.

Table 1: Trimester specific values for thyroid function tests. 4

\begin{tabular}{|lllll|}
\hline & $\begin{array}{l}\text { Units } \\
\text { TSH }\end{array}$ & $\begin{array}{l}1^{\text {st }} \\
\text { trimester } \\
\text { or } \\
\mathrm{mU} / \mathrm{ml}\end{array}$ & $\begin{array}{l}2^{\text {nd }} \\
\text { trimester }\end{array}$ & $\begin{array}{l}3^{\text {rd }} \\
\text { trimester }\end{array}$ \\
\hline $\mathrm{FT}_{4}$ & $\mathrm{ng} / \mathrm{dl}$ & $0.03-0.3$ & $0.03-3.7$ & $0.13-3.4$ \\
\cline { 2 - 5 } & $\mathrm{pmol} / \mathrm{L}$ & $11.1-22.9$ & $8.1-16.7$ & $8.5-14.4$ \\
$\mathrm{FT}_{3}$ & $\begin{array}{l}\mathrm{pmol} / \mathrm{L} \\
\mathrm{pg} / \mathrm{ml}\end{array}$ & $\begin{array}{l}3-5.7 \\
1.91-3,5 \\
\mathrm{pg} / \mathrm{ml}\end{array}$ & $2.8-4.2$ & $2.4-4.1$ \\
\hline
\end{tabular}

\section{RESULTS}

A total of 100 pregnant women who were hypothyroid were included in the present study and were divided into two groups as

- Group A: 50 women who were already known case of hypothyroidism before pregnancy and on oral thyroid hormone supplementation.

- Group B: 50 women who were diagnosed for the first time with hypothyroid on the first antenatal visit and were not on any medication before that.

\section{Prevalence of fetal complications in both the groups.}

Table 2: Fetal complications in both the groups.

\begin{tabular}{|lcccccc|}
\hline & \multicolumn{2}{c}{ Group A } & \multicolumn{2}{c|}{ Group B } & \multicolumn{2}{c|}{ Total } \\
\hline & No. & $\%$ & No. & $\%$ & No. & $\%$ \\
\hline $\begin{array}{l}\text { Preterm } \\
\text { babies }\end{array}$ & 01 & 02 & 03 & 06 & 04 & 08 \\
\hline $\begin{array}{l}\text { Low birth } \\
\text { weight }\end{array}$ & 05 & 10 & 11 & 22 & 16 & 32 \\
\hline $\begin{array}{l}\text { Fetal } \\
\text { distress }\end{array}$ & 07 & 14 & 09 & 18 & 16 & 32 \\
\hline
\end{tabular}

Present study suggested that rate of emergency lower segment cesarean section $(70 \%)$ is higher than elective lower segment cesarean section (30\%) which is significant. But the rate of elective lower segment cesarean section (59\%) as compared to emergency lower segment cesarean section (41\%). 
Table 3: Distribution of lower segment cesarean section in both the groups.

\begin{tabular}{|llllll|}
\hline & Group A & \multicolumn{2}{c|}{ Group B } & P-value \\
\hline Number & $\%$ & Number & $\%$ & \\
\hline Normal vaginal delivery & 32 & 64 & 25 & 50 & Significant $(<0.0005)$ \\
\hline Instrumental vaginal delivery & 01 & 02 & 02 & 04 & Significant $(<0.0005)$ \\
\hline LSCS & 17 & 34 & 23 & 46 & Significant $(<0.0005)$ \\
\hline
\end{tabular}

\section{Distribution of lower segment cesearian section.}

Table 4: Distribution of lower segment cesarean section in both the groups.

\begin{tabular}{|lllll|}
\hline LSCS & Group A & \multicolumn{2}{c|}{ Group B } \\
\hline Elective & No & $\%$ & No & $\%$ \\
\hline Emergency & 7 & 58.82 & 7 & 30.43 \\
\hline Total & 17 & 41.17 & 16 & 69.55 \\
\hline $\begin{array}{l}\text { P value } \\
\text { significant }(<0.0005)\end{array}$ & \multicolumn{3}{c|}{$\begin{array}{l}\text { P value } \\
\text { significant }(<0.0005)\end{array}$} \\
\hline
\end{tabular}

\section{Neonatal TSH of newborn at birth.}

Table 5: Neonatal TSH at birth.

\begin{tabular}{|llll|}
\hline $\begin{array}{l}\text { Neonatal } \\
\text { TSH at } \\
\text { birth }\end{array}$ & \multicolumn{2}{l}{ Group A } & \multicolumn{2}{c|}{ Group B } & \multicolumn{1}{c|}{ p-value } \\
Mean & 9.411875 & 8.73208 & $\mathrm{P}=0.3821$ \\
\hline SD & 3.9636 & 2.256 & Not significant \\
\hline
\end{tabular}

The mean neonatal TSH in group I is $9.4 \mathrm{mIU} / \mathrm{L}$ and in group II is $8.7 \mathrm{mIU} / \mathrm{L}$ which are non-significant.

\section{Perinatal outcomes}

Table 6: Perinatal outcome.

\begin{tabular}{|llcllll|}
\hline & \multicolumn{2}{c}{ Group A } & \multicolumn{2}{c|}{ Group B } & Total \\
\hline & No. & $\%$ & No. & $\%$ & No. & $\%$ \\
\hline $\begin{array}{l}\text { Apgar score at } \\
\text { 1min }\end{array}$ & 01 & 06 & 03 & 20 & 04 & 26 \\
\hline $\begin{array}{l}\text { Apgar score at } \\
5 \text { min }\end{array}$ & 05 & 04 & 11 & 12 & 16 & 12 \\
\hline $\begin{array}{l}\text { NICU } \\
\text { admission }\end{array}$ & 07 & 12 & 09 & 28 & 16 & 40 \\
\hline Normal at birth & 15 & 30 & 12 & 24 & 27 & 54 \\
\hline $\begin{array}{l}\text { Congenital } \\
\text { hypothyroidism }\end{array}$ & 00 & 00 & 01 & 02 & 01 & 02 \\
\hline
\end{tabular}

\section{DISCUSSION}

Thyroid disorders are common among pregnant women. Diagnosis of thyroid dysfunction is made difficult due to the association with non-specific symptoms, hypermetabolic state of pregnancy and thyroid physiology in pregnancy which results in the alteration in maternal serum TSH and thyroxine concentrations. If untreated, hypothyroidism may adversely affect the mother and fetus. Earlier studies have reported increased prevalence of congenital anomalies (10-20\%), perinatal mortality (20\%) and impaired mental and somatic development $(50-60 \%)$ in new born of untreated hypothyroid mothers. ${ }^{5,6}$

The prevalence of preterm babies (gestational age $<37$ weeks) in group $\mathrm{A}$ is found to be $2 \%$. And the prevalence of preterm babies in group B is $6 \%$. The present study shows the difference between the two groups are significant $\mathrm{p}$-value $<0.005$. The relative risk being 3 indicating that those mothers with poorly controlled thyroid status are three times more at risk of delivering preterm babies as compared to the mothers with well controlled thyroid group.

Preterm increased risk was also reported by Saki et al as well as by Mannisto et al. ${ }^{7,8}$ Preterm deliveries were higher in study by Kumru et al and Nazapour et al in the study in Turkey and Iran repsctively., 9

In a study conducted by Hirsch et al premature deliveries were found out to be $2.9 \%$ in clinical hypothyroid. ${ }^{11}$

The prevalence of low birth weight babies (birth weight less than $2.5 \mathrm{~kg}$ ) in group A is found to be $10 \%$. And the prevalence of preterm babies in group B is $22 \%$.

The present study shows the difference between the two groups are significant $\mathrm{p}$ value $<0.005$. The relative risk being 2.2 indicating that those mothers with poorly controlled thyroid status are two times more at risk of delivering low birth baby as compared to the mothers with well controlled thyroid group. Kumru et al reported higher incidence of low birth weight in mothers with clinical hypothyroidism. ${ }^{9}$

Nazarpour et al has also reported higher incidence of low birth weight in mothers with clinical hypothyroidism. ${ }^{10}$ Study done by Goel $\mathrm{P}$ et al to know the maternal and perinatal outcome in pregnancy with hypothyroidism showed that prevalence of LBW was $13.3 \% .^{12}$ 
The prevalence of fetal distress in group B is found to be $18 \%$. And the prevalence of fetal distress in group $\mathrm{A}$ is $14 \%$. The present study shows the difference between the two groups are significant p-value $<0.005$. The relative risk being 1.28 indicating that those mothers with poorly controlled thyroid status are more at risk of having fetal distress in baby as compared to the mothers with well controlled thyroid group.

Study done by Goel $\mathrm{P}$ et al to know the maternal and perinatal outcome in pregnancy with hypothyroidism showed that prevalence of fetal distress $20 \% .^{12}$ Maternal thyroid hypofunctions and pregnancy outcomes has also been studied in Western Countries by many authors including Glinoer et al Green $\mathrm{S}$ et al Negro et al and Abalovich et al. ${ }^{14-16}$ Their studies have established a strong association between the hypothyroidism and adverse pregnancy outcomes.

The caesarean section rates were higher in the present study group (40\%) including both emergency and elective caesarean sections. Among caesarean section, we further divided into elective and emergency indications. Rate of cesarean done for elective indication is higher in group A (59\%) as compared to group B with $30 \%$, the pvalue being (0.0005) is significant. The rates of emergency cesarean section in group B is $70 \%$ which is higher than group A with $41 \%$, the p-value being (0.0005) which is significant. The relative risk being 2.2 indicating that those mothers with poorly controlled thyroid status are twice more at risk of fetal distress as compared to the mothers with euthyroid group.

In present study $52 \%$ of emergency LSCS were done for meconium stained amniotic fluid. Mannisto et al in the study in United States found that Ceserean section rates were higher in pregnant women with hypothyroidism. ${ }^{8}$

The study by Sharma $\mathrm{P}$ et al showed that the rate of cesarean section in hypothyroid mothers was $28.2 \% .^{17}$ Kummu et al found no such association between thyroid dysfunction and cesarean section. ${ }^{9}$

The neonatal TSH at birth was also evaluated in both the groups. The normal range at birth being $1.7 \mathrm{mU} / \mathrm{L}$ to $9.1 \mathrm{mU} / \mathrm{L}$. The mean neonatal TSH in group $\mathrm{A}$ is $9.4 \mathrm{mIU} / \mathrm{L}$ and in the group $\mathrm{B}$ its $8.7 \mathrm{mIU} / \mathrm{L}$, there is no significant differences noted in both the groups $\mathrm{p}$-value $=0.3821$.

In addition, Marwaha et al have reported that normal range of thyroid hormones in the Indian pregnant women is higher as compared to international cutoffs. ${ }^{18}$

The large burden of subclinical hypothyroidism in pregnancy may prove to be a major public health burden in India, once it becomes clear that adverse outcomes can be corrected with screening and early replacement of levothyroxine. Children born to hypothyroid mothers have a poor intellectual function during the later part of their life. ${ }^{19}$

Therefore, majority of the developed countries have the National Neonatal Screening Program in place and routinely screen all newborn for hypothyroidism. The question whether to screen all pregnant women for hypothyroidism is still not resolved. ${ }^{20}$

ATA in its recently published guidelines has stated against the universal screening of pregnant women for hypothyroidism. ${ }^{21}$

\section{CONCLUSION}

In present study, the rate of emergency caesarean, rate of preterm birth, low birth weight babies and rate of foetal distress is significantly higher in mothers with poorly controlled thyroid status as compared to mothers with well controlled thyroid status. This difference can probably be explained by the fact that there could be higher unawareness in the former group. Hence we can conclude that early diagnosis and timely management of hypothyroidism in pregnancy is important to prevent maternofetal complications.

Learning from the present study as studies done before on Hypothyroid with pregnancy, thyroid function tests should be made mandatory in the tests of routine antenatal investigations of all mothers in ANC Clinic.

\section{ACKNOWLEDGEMENTS}

The authors would be thankful to Dr. S.K. Desai (Professor and Head of Unit), Dr. P. B. Pai (Professor and Head of Unit), Dr. C. M. Nariani (Professor and Head of Department) Dr. Pratima Chipalkatti (Associate Professor and Head of Unit), Dr. Prema Kania (Associate Professor and Head of Unit) from Department of Obstetrics and Gynecology from Bombay Hospital Institute of Medical Sciences, Mumbai, India.

Funding: No funding sources

Conflict of interest: None declared

Ethical approval: The study was approved by the Institutional Ethics Committee

\section{REFERENCES}

1. Glinoer D. The regulation of thyroid function in pregnancy: pathways of endocrine adaptation from physiology to pathology. Endocr Rev. 1997;18:40433.

2. Casey BM, Leveno KJ. Thyroid disease in pregnancy. Obstet Gynecol. 2006;108:1283-92.

3. Le Bean, Mandal SJ. Thyroid disorders during pregnancy. Endocrinal Metab Clin N Am. 2006;35:117-36. 
4. Panesar NS. Reference intervals for thyroid hormones in pregnant Chinese women. Ann Clin Biochem. 2001;38:329-32.

5. Goel P, Radotra A, Devi K, Malhotra S, Aggarwal A, Huria A. Maternal and perinatal outcome in pregnancy with hypothyroidism. Indian J Med Sci. 2005;59(3):116-7.

6. Glinoer D, Fernandez SML, Bourdoux P. Pregnancy in patients with mild thyroid abnormalities: maternal and neonatal repercussions. J Clin Endocrinol Metal. 1991;79:197-204.

7. Saki F, Dabbagmagnesh MH, Ghaeni SZ, Forouhari S, Ranjbar OG, Bakhshayesh KM. Thyroid function in pregnancy and its influence on maternal and fetal outcomes. Int Journal Endocrino Metab. 2014;12(4):19378.

8. Mannisto T, Mendola P, Grewal J, Xie Y, Chen Z, Laughan SK. Thyroid diseases and adverse pregnancy outcomes in a contemporary US cohort. Journal Clinical Endocrinology and Metabolism. 2013;98(7):2725-33.

9. Kumru P, Erdogdu E, Arisoy , Demirci O, Ozkoral A, Ardic C. Effect of thyroid dysfunction and autoimmunity and pregnancy outcomes in low risk population. Arch Gynecology Obstet. 2015;291(5):1047-54.

10. Nazarpour S, Ramezani T, Ani F, Simbar M, Azizi F. Thyroid dysfuctions and pregnancy outcomes. Iran J Reproductive Med. 2015;13(7):387-96.

11. Hirsch D, Levy S, Nadler V, Kopel V, Shainberg B, Toledano Y. Pregnancy outcomes in women with severe hypothyroidism. Europen $\mathrm{J}$ Endocrino. 2013;169(3):313-20.

12. Goel P, Radotra A, Devi K, Malhotra S, Aggarwal A, Huria A. Maternal and perinatal outcome in pregnancy with hypothyroidism. Indian J Med Sci. 2005;59(3):116-7.

13. Glinoer D, Fernandez SML, Bourdoux P. Pregnancy in patients with mild thyroid abnormalities: maternal and neonatal repercussions. J Clin Endocrinol Metal. 1991;79:197-204.
14. Stagnaro GA, Roman H, Cobin H. Detection at risk pregnancy by means of highly sensitive assays for thyroid autoantibodies. J Am Med Asso. 1990;264:1422-5.

15. Negro R, Formso G, Mangieri T, Pezzarossa A, Dazzi D, Hassan H. Levothyroxine treatment in euthyroid pregnant women with autoimmune thyroid disease: effects on obstetrical complications. J Clin Endocrinol Metab. 2006;91(7):2587-91.

16. Abalovich M, Gutierrex S, Alcaraz G, Maccallini GA, Levelle O. Overt and subclinical hypothyroidism complicating pregnancy. Thyroid. 2002;12:63-8.

17. Sharma P. Mukhopadhyay P, Mukhopadhyay A, Muraleedharan PD, Begum N. Hypothyroidism in pregnancy. J Obstet Gynecol India. 2007;57(4):3314.

18. Marwaha RK, Chopra S, Gopalakrishnan S, Sharma B, Kanwar RS, Sastry A, et al. Establishment of reference range for thyroid hormones in normal pregnant Indian women. British $\mathrm{J}$ Obst Gynae. 2008;115:602-6.

19. Negro R, Schwartz A, Gismondi R, Tinelli A, Mangieri T, Stagnaro GA. Universal screening versus case finding for detection and treatment of thyroid hormonal dysfunction during pregnancy. J Clin Endocrinol Metab. 2010;95:1699-707.

20. Vila L, Velasco I, Gonzalez S, Morales F, Sanchez $\mathrm{E}$, Torrejon S, et al. Controversies in endocrinology: on the need for universal thyroid screening in pregnant women. Eur J Endocrinol. 2013;170:17-30.

21. Stagnaro GA, Abalovich M, Alexander E, Azizi F, Mestman J, Negro R, et al. Guidelines of the American Thyroid Association for the diagnosis and management of thyroid disease during pregnancy and postpartum. Thyroid. 2011;21:1081-125.

22. Liz S. Updated aap guidelines on newborn screening and therapy for congenital hypothyroidism. Am Fam Physician. 2007;76(3):439-44.

Cite this article as: Shameel F, Tibrewala S, Afreen $\mathrm{S}$, Shetty R. To study the neonatal outcomes in pregnancies with hypothyroidism in a tertiary referral centre. Int J Reprod Contracept Obstet Gynecol 2016;5:2973-7. 